\title{
Liver Extraskeletal Osteosarcoma
}

National Cancer Institute

\section{Source}

National Cancer Institute. Liver Extraskeletal Osteosarcoma. NCI Thesaurus. Code C5833.

An osteosarcoma arising from the liver. 